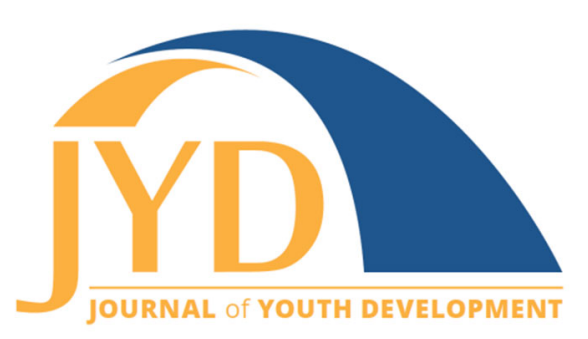

http://jyd.pitt.edu/ | Vol. 15 Issue 5 DOI 10.5195/jyd.2020.777 | ISSN 2325-4017 (online)

\title{
Next Generation Community Leaders Initiative: Collaborating With Youth to Develop Leaders and Healthier Communities
}

\author{
Robert L. Atkins \\ New Jersey Health Initiatives, Rutgers University-Camden \\ atkins@njhi.org

\section{Daniel Hart} \\ Institute for Educational Effectiveness, Rutgers University-Camden \\ daniel.hart@rutgers.edu \\ Susan Altman \\ Institute for Educational Effectiveness, Rutgers University-Camden \\ susan.altman@rutgers.edu
}

\begin{abstract}
Central to addressing the social determinants of health and challenges to health equity in the United States is the growing acknowledgement among solution seekers of the importance of cross-sector collaborators and partners. Youth are an underutilized and overlooked partner, especially in vulnerable urban communities, who bring diverse perspectives on their communities. Provided the opportunity and resources (e.g., coaching, compensation, and connections), youth can add value as partners to solve problems and achieve goals to benefit their communities. In this paper we review and discuss the Next Generation Community Leaders initiative (NGCL) a \$2.8 million initiative funded by New Jersey Health Initiatives, the statewide grantmaking program of the Robert Wood Johnson Foundation. We also describe findings from an independent evaluation of NGCL that explored how investments in youth through youth-serving organizations benefitted the youth who participated and increased health equity in their communities. Finally, we share 5 principles of youth engagement that we identified through our work as practitioners and scholars.
\end{abstract}

Key words: youth, partners, urban, community, equity

The past 2 decades have seen an increase in support for investing resources into creating civic engagement opportunities that engage youth. The best of these efforts support youth as

(cc) EY New articles in this journal are licensed under a Creative Commons Attribution 4.0 License. This journal is published by the University Library System, University of Pittsburgh and is cosponsored by the University of Pittsburgh Press. The Journal of Youth Development is the official peer-reviewed publication of the National Association of Extension 4-H Youth Development Professionals and the National AfterSchool Association. 


\section{Partnering With Youth}

partners in building healthier and more equitable communities. Opportunities for communities to partner with youth vary and can include community service, participation on youth councils, and youth organizing in which young people work collectively to address challenges to health and equity in their schools and communities (Kirshner \& Ginwright, 2012). These types of civic engagement efforts are associated with young people achieving healthy and constructive adulthoods-while contributing to the betterment of their communities (Levine, 2018; Zeldin et al., 2012).

Unfortunately, these types of civic engagement opportunities are not available to all young people. A growing body of evidence suggests that, while young people of color and youth living in low-income communities are motivated to engage civically, they have fewer opportunities than their more advantaged peers to engage in leadership opportunities, particularly those which contribute to their personal development and address community concerns (Ginwright, 2007; Govan et al., 2015; Hart \& Atkins, 2002; Kirshner \& Ginwright, 2012).

In this paper we discuss the Next Generation Community Leaders initiative and provide a brief summary of an independent evaluation of the program's ability to build civic habits and provide leadership pathways for youth living in low-income communities (Danley et al., 2020). This $\$ 2.8$ million initiative was funded by New Jersey Health Initiatives, the statewide grantmaking program of the Robert Wood Johnson Foundation. Ten youth-serving organizations (e.g., 4-H, Boys \& Girls Club) in low-income cities in New Jersey received $\$ 200,000$ grants and technical support from the Institute for Effective Education at Rutgers-Camden to create teams supported by coaches working to plan and implement projects that improved health in their communities.

An emphasis of the NGCL initiative was to invest resources into developing the civic habits and leadership skills of a representative sample of youth in the community. Consequently, in their funding proposals and site visits, applicant organizations had to describe the methods they would use to recruit, select and retain a diverse sample of youth (e.g., high-achieving students, typical and out-of-school youth) for participation in the initiative. Each youth-serving grantee created a team of 10-15 minority and low-income youth, with one or two adult coaches. The youth teams were integral to the initiative and grantees received technical assistance and guidance from the Institute for Effective Education in developing teams of youth who trusted each other and had a shared sense of identity 


\section{Partnering With Youth}

The initiative began with all 10 teams traveling to Camp Ockanickon in Medford, New Jersey in the fall for a weekend retreat. Over the course of the weekend, the teams and their coaches built communication skills and trust by working together to solve outdoor challenges (e.g., canoeing, ropes courses). Over the next 10 months the youth met regularly in their communities (three to four times/month).

The youth received technical assistance and coaching to explore their cities, facilitate conversations, and engage in discussions with community leaders (e.g., elected officials) and community-based organizations. With this support and guidance, the youth developed and implemented projects that addressed a challenge to health and health equity in their communities (see NGCL projects described on NJHI website). The projects ranged from addressing school absenteeism in Newark to improving food security among older adults in Atlantic City. The youth implemented the projects as their paid summer employment. All grantees had experience in serving youth living in low-income communities and were prepared to develop projects based on the NGCL logic model that included compensating youth, skilled coaches, and the development of logic models for their projects. The teams received technical assistance to develop logic models that promoted the team's understanding of a shared project, sharpened the team's efforts, and improved communication with community-based organizations.

The NGCL initiative created an interesting learning opportunity. The NGCL initiative funded 10 youth-serving organizations in New Jersey with each grantee engaging two teams of 10 to 15 youth over 2 years. Few philanthropic initiatives have invested in youth leadership development across an entire state, directly compensated youth for working as partners in building healthier communities, or funded an independent evaluation to test hypothesis around what inputs and resources are required to build civic habits and leadership skills in youth. As described in the evaluation report (Danley et al., 2020) the evaluation team used mixed methods to compare and contrast how differences across the sites such as the quality of adult coaches, the cohesion of youth teams, and the facilitation of conversations with community partners contributed to the civic development of youth and the implementation of successful projects.

Most of the ideas for the NGCL initiative came from the applied and research work we, Robert Atkins and Daniel Hart, have done together over the past 25 years. For 2 decades we ran a notfor-profit, youth-serving program in the city of Camden, New Jersey and we have co-authored several papers on civic engagement and youth development. In this paper we provide a brief 


\section{Partnering With Youth}

review of some of the theoretical work from youth development and youth organizing that guided the development of the NGCL initiative. We review the logic model that we used to connect theory and practice.

As part of the NGCL initiative, an independent team of evaluators was funded to test the logic model (Figure 1) and the conceptual model (Figure 2) which reflect the key constructs for the initiative: building and sustaining effective teams, youth agency through compensated and meaningful work, and relationships with adults who serve as coaches and community partners. The evaluators used mixed methods that included the administration of survey assessments at the following four time points: Baseline/Month 1 (i.e., the program kick-off at the initial youth retreat at YMCA Camp Ockanickon), Month 5 (i.e., after the development of preliminary plan at individual communities), Month 8 (i.e., immediately after the development and presentation of the youths' summer health projects), and post-programming/Months 11 and 12 (i.e., following the implementation of youths' health projects in individual communities). The results from the evaluation suggest that the NGCL model not only improves youth outcomes, but also supports youth in making meaningful contributions to the health of their communities. A link to the evaluation can be found in Danley et al. (2020). 
Partnering With Youth

Figure 1. Next Generation Community Leaders Project Logic Model/Theory of Change

\begin{tabular}{|c|c|c|c|c|}
\hline Resources & Activities & Outputs & Outcomes & Impact \\
\hline $\begin{array}{ll}\text { 1. } 10-15 \text { idealistic } \\
\text { youth with } \\
\text { leadership } \\
\text { potential } \\
\text { 2. }\end{array}$ & $\begin{array}{l}\text { 1. Team building } \\
\text { 2. Civic engagement } \\
\text { 3. Collaboration with } \\
\text { community } \\
\text { partners } \\
\text { 4. Development, } \\
\text { presentation, } \\
\text { revision, of logic } \\
\text { model/theory of } \\
\text { change } \\
\text { Implementation of } \\
\text { logic model/theory } \\
\text { of change }\end{array}$ & $\begin{array}{l}\text { 1. At least } 12 \\
\text { effective team } \\
\text { meetings (see } \\
\text { Rubric) between } \\
\text { September and } \\
\text { July } \\
\text { 2. At least } 10 \text { youth } \\
\text { participating at } \\
\text { each meeting } \\
\text { 3. Program director } \\
\text { and coaches } 95 \% \\
\text { participation at } \\
\text { meetings } \\
\text { 4. At least } 4 \\
\text { meetings with } \\
\text { community } \\
\text { partners } \\
\text { 5. At least } 10 \text { youth } \\
\text { participating } \\
\text { during } \\
\text { implementation }\end{array}$ & 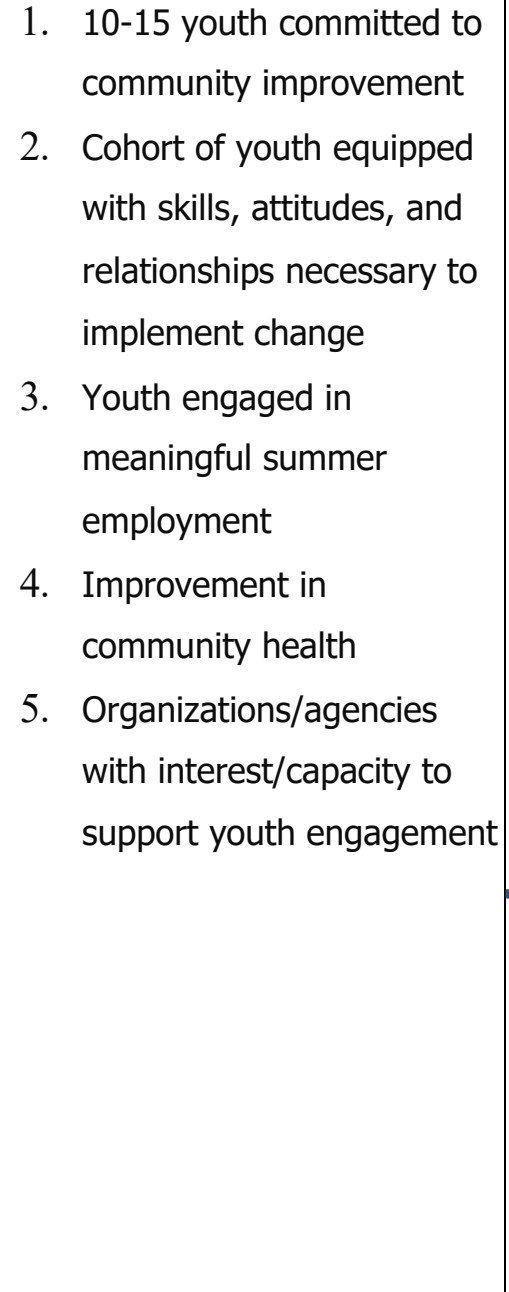 & $\begin{array}{l}\text { 1. } \begin{array}{l}\text { Cohort of young } \\
\text { adults committed } \\
\text { to community } \\
\text { leadership }\end{array} \\
\text { 2. Cohort of young } \\
\text { adults } \\
\text { knowledgeable } \\
\text { about community } \\
\text { health } \\
\text { Community open } \\
\text { to and valuing of } \\
\text { youth } \\
\text { engagement }\end{array}$ \\
\hline
\end{tabular}


Partnering With Youth

Figure 2. Next Generation Community Leaders Conceptual Model

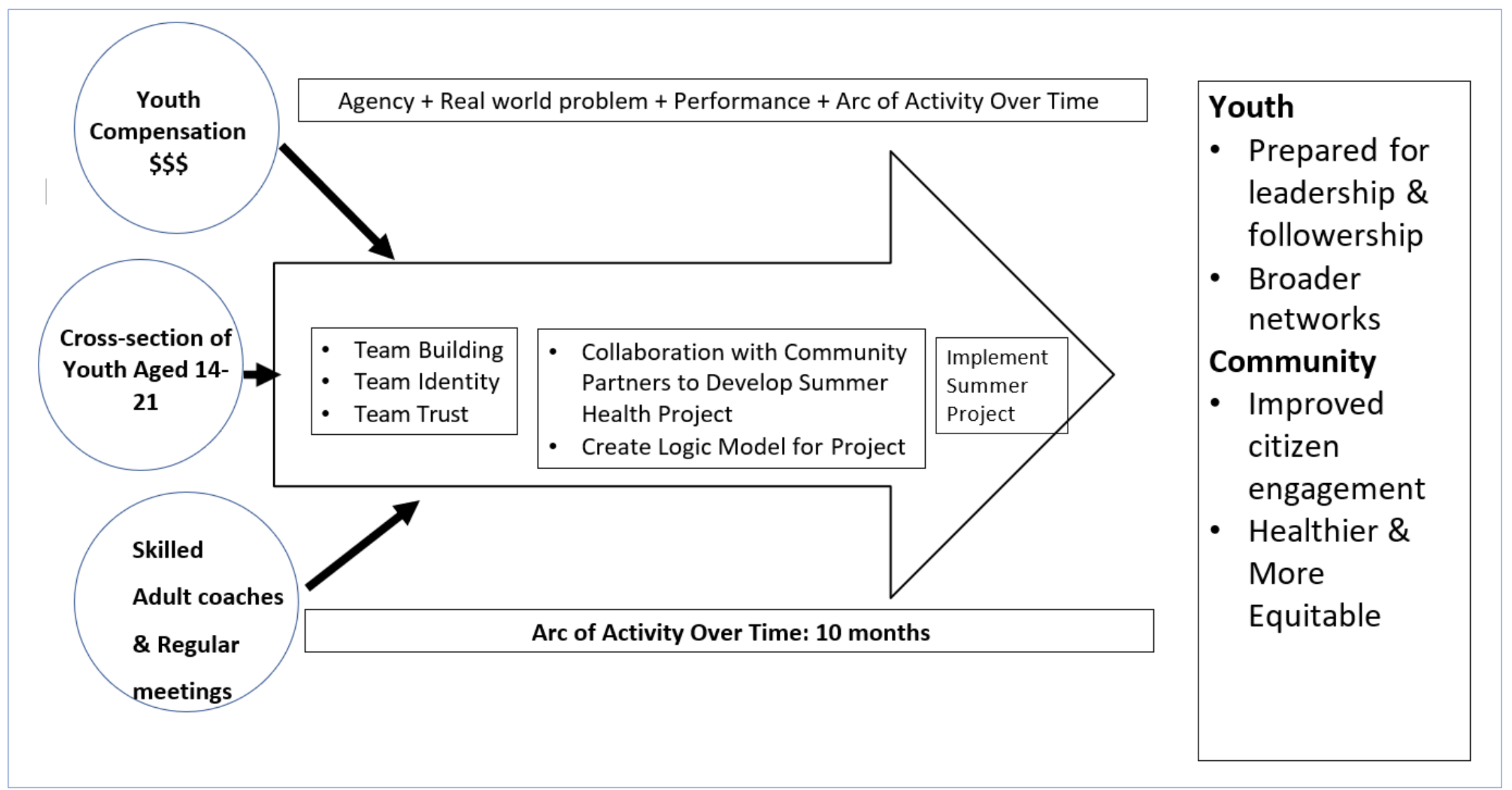




\section{Review of Literature}

Larson (2000) examined civic engagement in the community from a youth development perspective. He argued that the emerging challenges of the $21^{\text {st }}$ century will require today's youth to develop initiative. Larson described this characteristic as the "capacity to exert cumulative effort over time to reinvent themselves, reshape their environments, and engage in other planful undertakings" (p. 171). Changes in cognition (e.g., deduction and reasoning) during adolescence create a valuable window of opportunity for youth to develop initiative. Larson identified three common features of effective youth organizations which provide participants the opportunity to develop initiative: (a) youth have agency (b) to address real world challenge and complexity, and (c) over time, develop a product or performance.

Larson's work intersects with that of other scholars interested in civic engagement. Some of these scholars have focused on youth organizing as an important pathway for young people who are marginalized because of factors such as their race, socio-economic status, or access to quality education. For example, Govan and colleagues (2015) conducted a study of international youth community organizing, seeking to develop marginalized youth as leaders in their communities. They emphasized the importance of adult-youth relationships and peer-peer relationships in building youth efficacy, agency, and commitment to their organization. Using the same data, Watts and colleagues (2018) emphasized the importance of relationships within the context of an organizing culture. They emphasized the importance of a learning process that includes cycles of preparation, rehearsal, performance, and feedback from peers and supportive adults.

\section{Connecting Theory and Practice}

The NGCL initiative provided youth-serving organizations in New Jersey with the financial and technical resources needed to develop youth into knowledgeable and effective civic actors in their communities. As reflected in the conceptual model (see Figure 2), we operationalized theories from youth development and civic engagement. For example, in order to build youth efficacy, agency, and commitment to the project goals, adult coaches organized youth into cohesive teams. Youth were organized into teams to provide a space for them to explore and invest in a new understanding of their communities through intentional and well-structured interactions with nonprofits, local governments and political leaders. This process provided another opportunity for youth agency: In partnership with adults, youth developed a 


\section{Partnering With Youth}

challenging and meaningful project that they were responsible for implementing. As they moved through the year-long process, youth developed the skills and experience they needed to participate as civic actors. At the same time, community institutions became better at engaging with a broad range of constituents, and when well-planned projects by youth were grounded in research and local knowledge, communities became healthier and more equitable.

It is important to emphasize that through the release of the call for proposals, review process (e.g., proposal review, site visits), and grantee training, we sought to connect theory and practice. For example, to increase the likelihood that the NGCL initiative would address inequality in leadership opportunities for marginalized young people, youth-serving organizations had to provide plans for recruiting and retaining youth who were not likely to receive leadership development (e.g., out-of-school youth). To demonstrate to youth that their time, talent, and energy were valued, youth-serving organizations had to provide detailed descriptions for how they would compensate youth and how youth would be supported in developing summer employment projects that benefited the youth and the community. Certain types of activities, like picking up trash in the park or filing papers in an office setting, were deemed unacceptable because they did not engage youth as civic leaders and/or contribute to health and well-being in the community. It was our goal to develop and implement a program that prioritized best practices from the academic literature and reflected what we had learned through our work with youth.

\section{Discussion}

Youth-centered civic engagement is valuable to the health and well-being of youth and the communities they live in. We developed the logic model for this initiative out of our two decades of experiences running a youth-serving program in Camden and a thorough review of the evidence. The goals of the NGCL initiative were to produce meaningful and measurable community health benefits through the mobilization of youth marginalized by zip code, access to resources, or race, and to prepare the next generation of leaders committed to building healthier and more equitable communities. As discussed, an independent evaluation of the logic model that guided the NGCL initiative suggested that the approach implemented through this funding initiative contributed to the development of youth as future leaders and civic actors.

Our findings from this statewide initiative converge with the findings others have made on developing youth as leaders and civic partners (Bates et al., 2019). In the discussion, we 


\section{Partnering With Youth}

highlight the five principles central to the NGCL approach that we implemented through this initiative.

\section{Make Youth and Adults Equal Partners}

The first principle is that the time, talent, and energy of youth has value to the community. In keeping with that principle, youth organizations were required to compensate youth for the hours they spent in the selection, design, and implementation of their community change projects. The youth received 11 months of coaching and assistance to develop projects that were achievable in 4 weeks of the summer, aligned with the skills and resources of the youth, and improved health for members of their community. Implementing the community change projects provided the youth paid summer employment. For many youth, especially youth in the most distressed communities, summers are a time of the year in which they have the largest blocks of free time and face the greatest risks to their health and well-being (Heller, 2014). As reflected in the conceptual model (Figure 2), youth develop civic habits and leadership skills by developing and implementing their ideas for improving health in their communities. In a couple of cities in New Jersey, for example, the youth team was interested in creating safer neighborhoods. They worked with Public Service Electric and Gas (PSE\&G), a utility company, their mayors, and local police to replace broken streetlights and beautify public spaces.

\section{Connect Youth to Community Leaders}

Leadership requires collaboration. NGCL youth consulted with and were informed by community leaders such as mayors, school superintendents, and police chiefs. In all of the NGCL projects youth formed relationships with community leaders (e.g., elected officials, executive directors of community-based organizations) who, along with their coaches, provided information on challenges in the community and assets that could be tapped to address those challenges. In one city, the mayor identified food security as a community challenge. Working with the mayor as a thought partner, the youth developed a project to increase the number of children and families enrolled in the U.S. Department of Agriculture's summer feeding program.

\section{Leverage Existing Assets in Community}

The third principle that we followed is that youth projects should be connected to existing institutions and the efforts of those institutions. Communities become healthier and more equitable when underutilized assets, like youth, are engaged as partners. For the same reason, 


\section{Partnering With Youth}

youth projects must be embedded in institutions and organizations that provide support and guidance. Schools, non-profits, and municipal governments were just some of the organizations that partnered with the youth in developing project ideas. In Atlantic City the NGCL youth team partnered with local food banks and other community-based organizations to create a better system for allocating food and promoting food distribution locations. Beyond providing support and guidance in the development of projects, these institutions and organizations shared other resources and assets (e.g., transportation, storage space) that allowed the youth to successfully implement their projects.

\section{No Skimming}

A fourth principle of the NGCL was that youth teams had to reflect the diversity of youth in the community. Grantees were discouraged from "skimming" to create teams primarily composed of high-achieving youth. High-achieving youth are often overrepresented among youth leadership programs and, especially in distressed communities, the highest achieving youth are more likely than their lower achieving peers to have educational and employment opportunities that decrease the likelihood they will stay in the community (Kress, 2006). We wanted to ensure that the youth-serving organizations funded through NGCL invested resources in developing the civic habits and leadership skills of "typical" youth who were more likely to stay in the community. In a few years, youth will be the adults who serve on the school board, run for city council, and act as coaches for youth programs.

\section{Arc of Time}

The fifth principle of NGCL was that the creation of youth groups and the development and implementation of civic/leadership projects were not open-ended. Youth-serving organizations were awarded the resources to recruit and shape two teams of 10 to 15 youth. This process of forming teams took a little less than 12 months and by the end of that year the team had developed projects that could be implemented in 1 month of the summer. This principle addresses equity in at least two ways. Youth increase equity in their communities by implementing manageable and meaningful projects that increase the opportunity for their families and neighbors to live healthier lives. In addition, by "turning over" the teams within a year, more than one cohort of youth are able to benefit from the experience and develop the skills to engage and lead community change. 
Partnering With Youth

\section{Conclusions}

To address inequalities in opportunities for high quality, youth-centered civic engagement, efforts have to move beyond 1-day community service efforts or listening tours. At the same time, to mobilize a greater number of marginalized youth, youth-centered civic engagement needs to be based on the best evidence, focused on teams of youth that reflect the community at large (e.g., do not just invest in honor-roll students), and intentional about time (e.g., engagement can't stretch on forever, but should also not be a one-shot listening tour). As discussed, the $1^{\text {st }}$ year of NGCL evaluation suggests that the NGCL approach has merit-youth and their communities benefitted. In less than 1 year, youth participants in NGCL developed new knowledge and skills as they worked to improve health in their communities.

While more than $95 \%$ of healthcare spending in the United States goes towards medical services, these types of "downstream" services account for only a fraction of our nation's health and well-being. As much as $70 \%$ of health can be attributed to the "upstream" or fundamental causes of poor health and inequity such as food insecurity, educational attainment and public safety (Bharmal et al., 2015). Addressing these challenges to health and health equity requires a change in how solution seekers think about improving health. These changes include leveraging a creative cross-sector of assets and engaging youth and other community stakeholders.

The NGCL initiative demonstrated that youth are valuable stakeholders who can be supported to identify health challenges and work with their communities to address those challenges. Youth are an underutilized asset, especially in vulnerable urban communities, where up to $40 \%$ of the population is under the age of 18 . The NGCL initiative supported communities in leveraging up to 2400 hours of youth time, talent, and energy. The youth were provided the resources they needed-coaching, compensation, and connections to leaders in their communities (e.g., elected officials, chiefs of police)-to lead changes that improved health and well-being in their communities.

Cross-sector collaborations and partnerships between individuals and organizations from nonprofit, government, philanthropic and business sectors are central to improving health and well-being in the United States (Towe, et al., 2016). Youth in this nation have a history of being important collaborators and partners in leading important civic movements (e.g., the civil rights movement of the 1960s). Most recently, youth from Parkland, Florida and other communities have shown themselves to be important partners in driving a critical conversation around gun 
violence and gun control (Alter, 2018). The findings from the evaluation of the NGCL initiative suggest more emphasis and resources be directed towards collaborating and partnering with youth-especially youth in vulnerable communities. With sufficient resources and opportunities, all youth in the community-from the highest-achieving to those who are disconnected from institutions like school—can learn leadership and participate as partners and collaborators in addressing challenges to health and health equity.

\section{References}

Alter, C. (2018). The school shooting generation has had enough. Time. http://time.com/longform/neveragain-movement/

Bates, S., Anderson-Butcher, D., Niewoehner-Green, J., \& Provenzano, J. (2019). Exploration of a college and career readiness leadership program for urban youth. Journal of Youth Development, 14(3), 160-182. https://doi.org/10.5195/jyd.2019.664

Bharmal, N., Derose, K. P., Felician, M., \& Weden, M. (2015). Understanding the upstream social determinants of health. Rand Corporation. Retrieved December 1, 2018 from https://www.rand.org/content/dam/rand/pubs/working papers/WR1000/WR1096/RAND WR109 6.pdf

Danley, S., Lu, W., Mitsdarffer, M. L., White, S., Perry, A., Razi, L., Craig, P. J., Williams, C., Kumari, R., \& McCaffrey, M. (2020). Next generation community leaders year one evaluation. New Jersey Health Initiatives; Rutgers University. shorturl.at/bcST0

Ginwright, S. (2007). Black youth activism and the role of critical social capital in Black community organizations. American Behavioral Scientist, 51(3), 403-418. https://doi.org/10.1177/0002764207306068

Govan, R., Fernandez, J., Lewis, D., \& Kirshner, B. (2015). International perspectives on youth leadership development through community organizing. New Directions For Student Leadership, 2015(148), 87-99. https://doi.org/10.1002/yd.20155

Hart, D., \& Atkins, R. (2002). Civic competence in urban youth. Applied Developmental Science, 6(4), 227-236. https://doi.org/10.1207/s1532480xads0604 10

Heller, S.B. (2014). Summer jobs reduce violence among disadvantaged youth. Science, 346, 1219-23.

Kirshner, B., \& Ginwright, S. (2012). Youth organizing as a developmental context for African American and Latino adolescents. Child Development Perspectives, 6(3), 288-294. https://doi.org10.1111/j.1750-8606.2012.00243.x

Kress, C. A. (2006). Youth leadership and youth development: Connections and questions. New Directions for Youth Development, 2006(109), 45-56. https://doi.org/10.1002/yd.154 
Journal of Youth Development | http://jyd.pitt.edu/ | Vol. 15 Issue 5 DOI 10.5195/jyd.2020.777

\section{Partnering With Youth}

Larson, R. (2000). Toward a psychology of positive youth development. American Psychologist, 55(1), 170-183. https://doi.org/10.1037/0003-066x.55.1.170

Towe, V., Leviton, L., Chandra, A., Sloan, J., Tait, M., \& Orleans, T. (2016). Cross-sector collaborations and partnerships: Essential ingredients to help shape health and well-being. Health Affairs, 35(11), 1964-1969. https://doi.org/10.1377/hlthaff.2016.0604

Zeldin, S., Christens, B. D., \& Powers, J. L. (2012). The psychology and practice of youth-adult partnership: Bridging generations for youth development and community change. American Journal of Community Psychology, 51(3-4), 385-397. https://doi.org/10.1007/s10464-012-9558-y 